Classification

Physics Abstracts

$61.16 \mathrm{~d}-\mathrm{S} 10.15$

\title{
Ordering phenomena in the diphosphate tungsten bronzes with hexagonal tunnels : $\mathrm{Ba}\left(\mathbf{P}_{2} \mathrm{O}_{4}\right)_{2}\left(\mathrm{WO}_{3}\right)_{2 m}$
}

\author{
Bernadette Domengès, Maryvonne Hervieu and Bernard Raveau
}

Laboratoire de Cristallographie et Sciences des Matériaux (CRISMAT), ISMRa, Boulevard du Maréchal Juin, 14032 Caen Cedex, France

(Received January 10, accepted March 2, 1990)

\begin{abstract}
Résumé. - Les phénomènes de surstructure dans les bronzes diphosphates de tungstène à tunnels hexagonaux au baryum, $\mathrm{Ba}\left(\mathrm{P}_{2} \mathrm{O}_{4}\right)_{2}\left(\mathrm{WO}_{3}\right)_{2 m}$, sont caractérisés par diffraction électronique et microscopie électronique haute résolution. Un modèle de surstructure est déduit des observations et utilisé dans les calculs de simulation d'images. La comparaison des images expérimentales et calculées permet d'associer aux phénomènes de surstructure, des mises en ordre des cations baryum dans les tunnels de section hexagonale.
\end{abstract}

\begin{abstract}
Superstructure phenomena in the barium diphosphate tungsten bronzes with hexagonal tunnels, $\mathrm{Ba}\left(\mathrm{P}_{2} \mathrm{O}_{4}\right)_{2}\left(\mathrm{WO}_{3}\right)_{2 m}$, are characterized by electron diffraction and high resolution electron microscopy. A model of superstructure is deduced from the observations and used to perform image calculations. The comparison of experimental and calculated images allows to associate the superstructure phenomena to orderings of the barium cations in the hexagonal tunnels.
\end{abstract}

\section{Introduction.}

A thorough study of the diphosphate tungsten bronzes with hexagonal tunnels $\left(\mathrm{DPTB}_{\mathrm{H}}\right)$ has been performed by high resolution electron microscopy [1-4] after the synthesis of the first crystal and its study by X-ray diffraction [5]. Complex nonstoichiometry phenomena have been characterized in this structural family with general composition $\mathrm{A}_{x}\left(\mathrm{P}_{2} \mathrm{O}_{4}\right)_{2}\left(\mathrm{WO}_{3}\right)_{2 m}$ especially for $\mathrm{A}=\mathrm{K}, \mathrm{Ba}(m \leq 20)$. A peculiar aspect of the $\mathrm{DPTB}_{\mathrm{H}}$ 's with barium consists in the great number of electron diffraction patterns [4] showing superstructure spots with respect to the classical cell. This was interpreted in a first approach as an ordering of the $\mathrm{P}_{2} \mathrm{O}_{7}$ groups and also of the barium ions in the hexagonal tunnels. However the HREM investigation, performed with a $120 \mathrm{kV}$ electron microscope did not allow a structural model to be established owing to the too low resolution. This work tries to characterize structurally the most common superstructure, using a $200 \mathrm{kV}$ high resolution electron microscope and image calculations. 


\section{Structural recalls.}

The DPTB ${ }_{\mathrm{H}}$ ' structure is based on $\mathrm{ReO}_{3}$-type slabs $\left(\mathrm{WO}_{3}\right)_{m}$ joined, parallely to $(102)_{\mathrm{ReO}_{3}}$, through $\mathrm{P}_{2} \mathrm{O}_{7}$ groups (Fig. 1). At the junction, hexagonal tunnels are formed which contain the A cation. The $\mathrm{Ba}-\mathrm{DPTB}_{\mathrm{H}}$ crystals usually show the symmetry $\mathrm{A} 2 / m$ in a cell defined by : $a$ parameter related to one mixed slab width, $b$ parameter to two octahedra height and $c$ parameter to twice the distance between two successive hexagonal tunnels (Fig. 1). (010)* and (001)* electron diffraction patterns are thus characterized by the existence conditions : $h 0 l, l=2 n$ and $h k 0, k=2 n$, respectively. The X-ray study on $\mathrm{Ba}\left(\mathrm{P}_{2} \mathrm{O}_{4}\right)_{2}\left(\mathrm{WO}_{3}\right)_{16}$ single crystal [6] has shown the existence of two structural domains which differ by the respective position of $\mathrm{P}_{2} \mathrm{O}_{7}$ groups forming the hexagonal tunnels (Fig. 2).

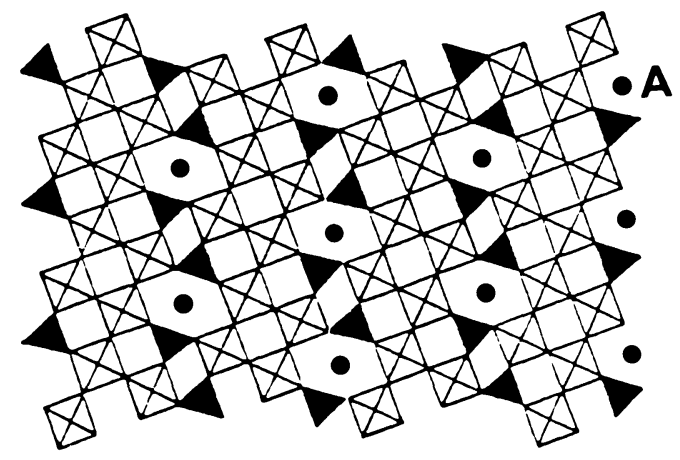

Fig. 1. - Idealized structure of $\mathrm{A}_{x}\left(\mathrm{P}_{2} \mathrm{O}_{4}\right)_{2}\left(\mathrm{WO}_{3}\right)_{8} ; m=4$ member of DPTB $\mathrm{H}_{\mathrm{H}}$ family, projected onto (010).

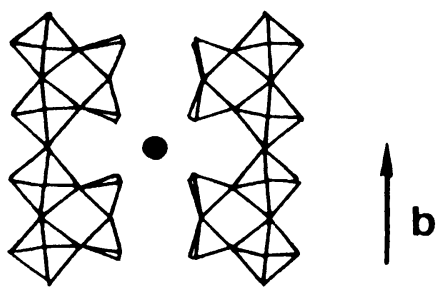

$\mathrm{Ba}$

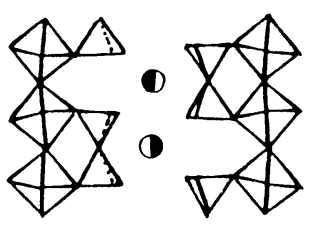

$1 / 2 \mathbf{B a}$

Fig. 2. - Partial projection parallel to [100] of $\mathrm{Ba}\left(\mathrm{P}_{2} \mathrm{O}_{4}\right)_{2}\left(\mathrm{WO}_{3}\right)_{16}$ structure showing the relative position of $\mathrm{P}_{2} \mathrm{O}_{7}$ groups forming the hexagonal tunnels in domains I and II.

\section{Experimental.}

Usual synthesis method was used : decomposition of a $\mathrm{BaCO}_{3},\left(\mathrm{NH}_{4}\right)_{2} \mathrm{HPO}_{4}$ and $\mathrm{WO}_{3}$ mixture, then after addition of metallic tungsten to the $\mathrm{Ba}_{x}\left(\mathrm{P}_{2} \mathrm{O}_{4}\right)_{2}\left(\mathrm{WO}_{3}\right)_{2 m}$ stoichiometry heating in evacuated silica tubes. Trying to favor the cation orderings, final heatings were performed during 15 days at $1100^{\circ} \mathrm{C}$. The preparations with the nominal composition $\mathrm{Ba}_{1.2}\left(\mathrm{P}_{2} \mathrm{O}_{4}\right)_{2}\left(\mathrm{WO}_{3}\right)_{12}$ and 
$\mathrm{Ba}_{x}\left(\mathrm{P}_{2} \mathrm{O}_{4}\right)_{2}\left(\mathrm{WO}_{3}\right)_{18}(x=1,1.2)$, respectively identified by X-ray powder diffraction as $m=6$ and $8 \mathrm{DPTB}_{\mathrm{H}}$ pure phases, were chosen for this study.

Electron diffraction study was performed on a side entry JEM $120 \mathrm{CX}$ and high resolution images obtained on a JEM $200 \mathrm{CX}$ equipped with a top-entry goniometer $\left( \pm 10^{\circ}\right)$ and an objective lens with a spherical aberration constant $C_{\mathbf{s}}=0.8 \mathrm{~mm}$. Lattice images were computed by use of the multislice method [7].

\section{Electron diffraction results.}

Among the numerous crystals which were observed, most of them exhibit superstructure spots as previously described [4]. Six crystals were selected which were characterized by a wellestablished superstructure. For three of them, reflections could be indexed in the complete reciprocal space, leading to the supercell $2 a \times b \times c$ and the $\mathrm{C} 2 / m$ space group $(h k l, h+k=2 n)$. In the three other crystals, several planes, in zone with $[100]^{*}$ reciprocal axis, show reflections which can only be indexed in the supercell. During the study, any crystal showing ED patterns with superstructure spots can be assigned the $\mathrm{C} 2 / \mathrm{m}$ space group in the supercell $2 a \times b \times c$. Thus, for both observation directions in high resolution work, [010] and [001], the ED patterns following the existence conditions :

$h 0 \ell$ no condition, equivalent to $h^{\prime} 0 l^{\prime} h^{\prime}=2 n$ and $a^{\prime}=2 \times a$

or $h^{\prime} k^{\prime} 0, h^{\prime}+k^{\prime}=2 n$ and $a^{\prime}=2 \times a$ (Fig. 3 )

will be considered as characteristic of the symmetry C $2 / m$ in the supercell $2 a \times b \times c$.

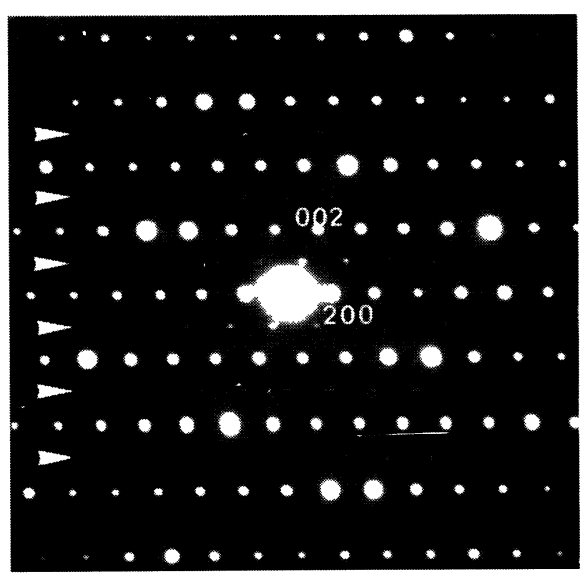

a)

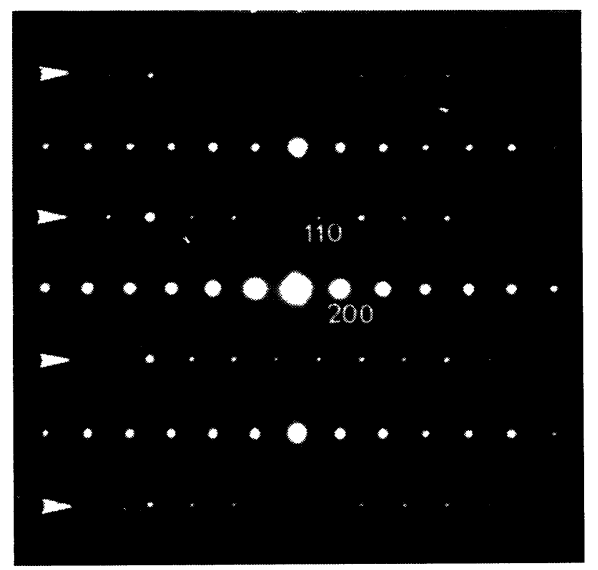

b)

Fig. 3. - ED patterns characteristic of the $2 a \times b \times c$ superstructure. Spots are indexed in the supercell and show the systematic existence conditions : a) $h 0 l, h=2 n$, b) $h k 0 h+k=2 n$.

\section{High resolution electron microscopy.}

This study has been performed on a JEM 200 CX which operates with an accelerating voltage of $200 \mathrm{kV}$. Such a high voltage appeared necessary to enhance ordering phenomena related to the cation content in the hexagonal tunnels and with limited effect of electron irradiation. Image calculations were performed to confirm contrast interpretation of high resolution images. Figure 4 shows a [010] calculated through-focus series based on crystallographic data from $\mathrm{Ba}\left(\mathrm{P}_{2} \mathrm{O}_{4}\right)_{4}\left(\mathrm{WO}_{3}\right)_{16} \mathrm{X}$-ray single crystal study for a crystal thickness of $2.24 \mathrm{~nm}$. Two values of 
defocus give a direct projection of the structure : when low electronic density zones are enhanced (close to $-20 \mathrm{~nm}$ ), tunnels of the structure - perovskite-type, hexagonal and rhombic - appear as bright dots, when high electronic density zones are enhanced (close to $-70 \mathrm{~nm}$ ), heavier atoms of the structure are imaged - tungsten, barium and phosphorus of $\mathrm{P}_{2} \mathrm{O}_{7}$ groups.

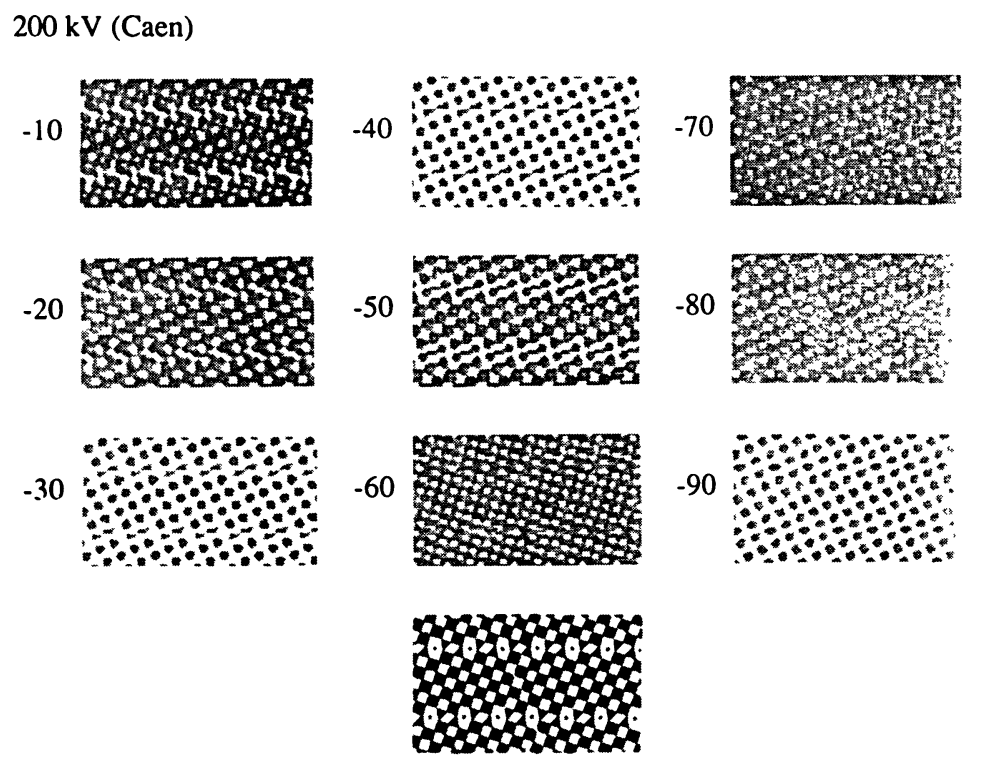

Fig. 4. - [010] calculated through-focus series with the parameters : high voltage $V=200 \mathrm{kV}$, spherical aberration $C_{\mathrm{s}}=0.8 \mathrm{~mm}$, convergence half-angle $\alpha / 2=0.8 \mathrm{mrad}$, focus spread $\Delta / 2=7.5 \mathrm{~nm}, 113$ beams in the objective apecture, crystal thickness $T=2.24 \mathrm{~nm}$. The attached projection of $\mathrm{Ba}\left(\mathrm{P}_{2} \mathrm{O}_{4}\right)_{2}\left(\mathrm{WO}_{3}\right)_{16}$ gives the correspondence between contrast and structure.

Twelve crystals have been studied. The ED patterns of nine of them show superstructure spots which intensity varies with the crystal. Parallely, the corresponding images exhibit a contrast more or less affected by the apparent superstructure.

$[010]$ projection direction.

ED PATTERNS WITHOUT ANY SUPERSTRUCTURE SPOTS. - Crystals which E.D. patterns do not show any superstructure spots were studied as a reference in a first step. Besides crystal images which show the classical contrast of $\mathrm{DPTB}_{\mathrm{H}}$ structure, some are characterized by a variation of intensity of the bright dots associated to the hexagonal tunnels of the structure (Fig. 5). At this defocus value, close to $-25 \mathrm{~nm}$, the square array of small bright dots $\left(3.8 \times 3.8 \AA^{2}\right)$ is associated to the perovskite-type tunnels of the structure. Parallely to the (102) $\mathrm{ReO}_{3}$ plane and regularly spaced $\left(d_{100}\right)$, alternate groups of two bright dots and a smaller one, which correspond to the hexagonal and rhombic tunnels respectively. The hexagonal tunnels appear as two bright dots instead of one because of the presence of the barium. On the right side of the image, following the row of alternating groups of two bright dots and smaller one, i.e. hexagonal and rhombic tunnels, one can notice a local variation of brightness of the two bright dot groups (arrowed in Fig. 5). According to Hutchison's observations in $\mathrm{Ba}_{0.04} \mathrm{WO}_{3}[8]$, this phenomena could be due to a local variation of barium content in the hexagonal tunnels. 


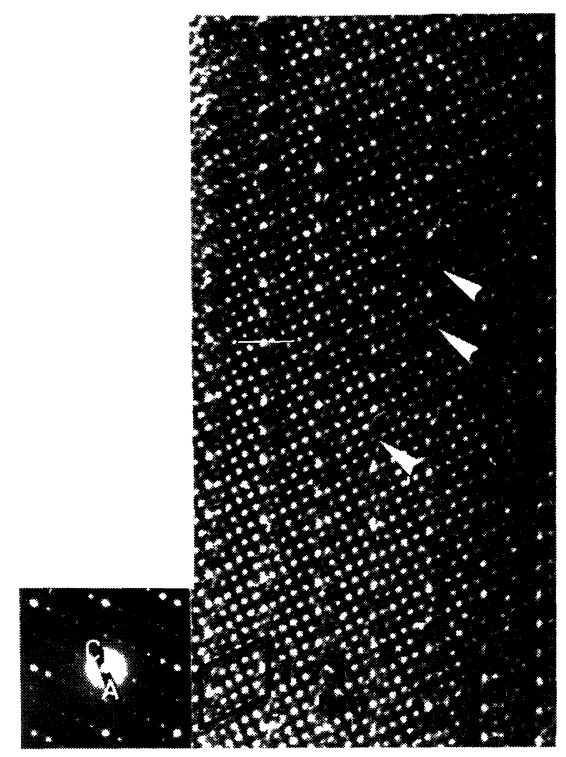

Fig. 5. - a) [010] ED pattern without any superstructure spots, b) corresponding high resolution image showing local variation of brightness of the two-dot groups associated to the hexagonal tunnels of the structure (arrowed).

ED PATTERNS WITH SUPERSTRUCTURE SPOTS. - When the extra reflections are weak, the corresponding images do not let appear any variation of the contrast, except on the thicker part where a modulation of bright dots introduce the periodicity $a \times c$ (to be opposed to the usual $a \times c / 2$ periodicity of this projection).

When extra reflections on the ED pattern suggest a well-established superstructure, image contrast hardly confirms its establishment. In figure 6 , only a very localized area, following the crystal line, is characterized by a brightness of dots introducing the periodicity $a \times c$. The observation of the experimental through-focus series has allowed to discard the hypotheses of a bending or a step of the crystal. First, this area stays parallel to the crystal line and is not associated to any perturbation of the contrast (such as contrast inversion at a step). Second, it moves with the defocus leading to the idea that given a defocus value, only the area with the adequate thickness show the contrast with $a \times c$ periodicity. A variation of barium content could be made responsible for this contrast modulation. The question is the apparent localization of this effect. It appears necessary to evaluate the contrast sensitivity to barium content versus defocus and thickness.

\section{[001] projection direction.}

This observation direction gives a good description of the stacking of $\mathrm{P}_{2} \mathrm{O}_{7}$ groups and barium atoms parallely to the $b$ axis (Fig. 7). The cation sites appear in the middle of a rhombic window, much smaller than viewed along [010]. We expect, thus, a higher sensitivity of the contrast to barium content. Nevertheless, the $\mathrm{ReO}_{3}$-type slabs appear on the projected potential as the succession of high electronic density zones (tungsten, phosphorus and oxygen of tungsten plane atoms) and light electronic density zones (other oxygen apexes). Thus, calculated images will again be necessary to interpret the observed contrasts. 
a)
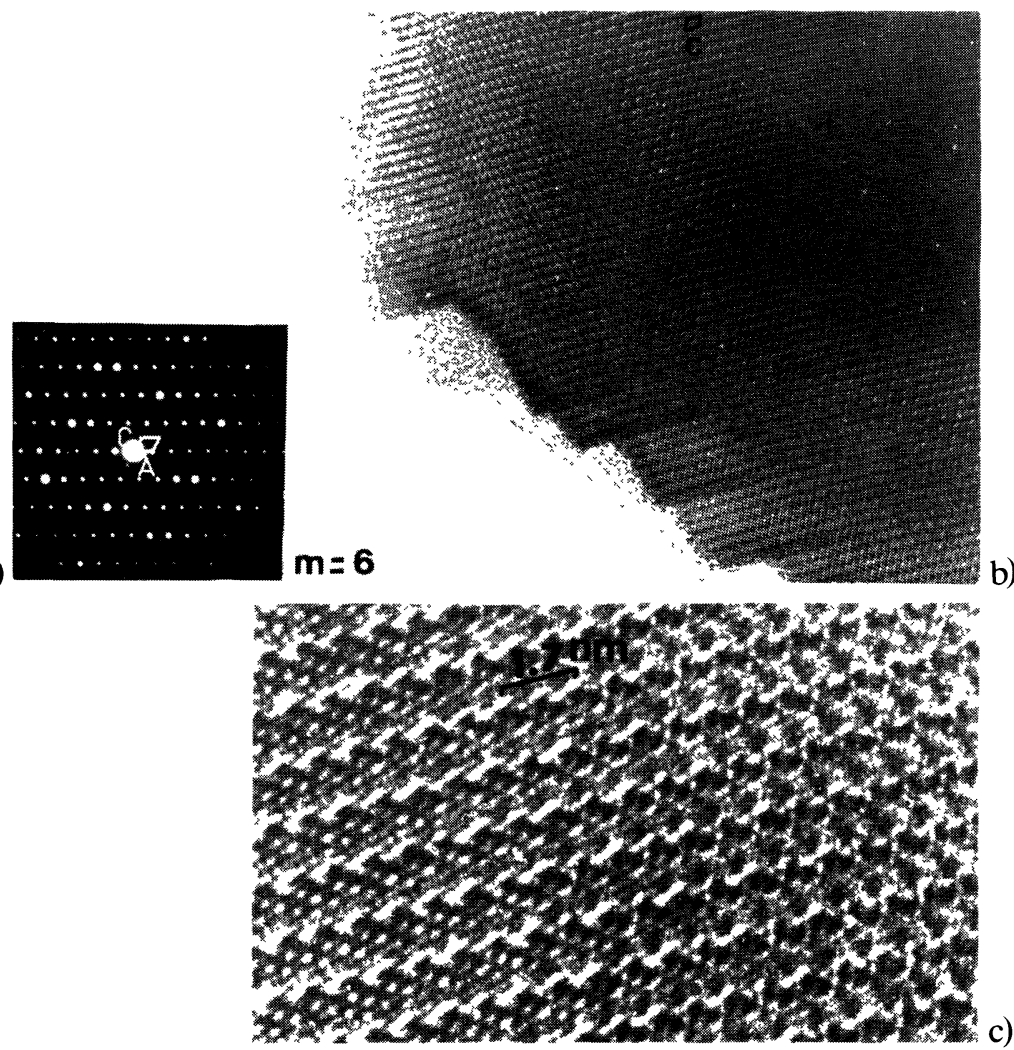

Fig. 6. - a) [010] ED pattern with superstructure spots b) corresponding high resolution image c) detail of a thick area, showing at a constant distance from the crystal edge, a distribution of brighter dots following the $a \times c$ periodicity.

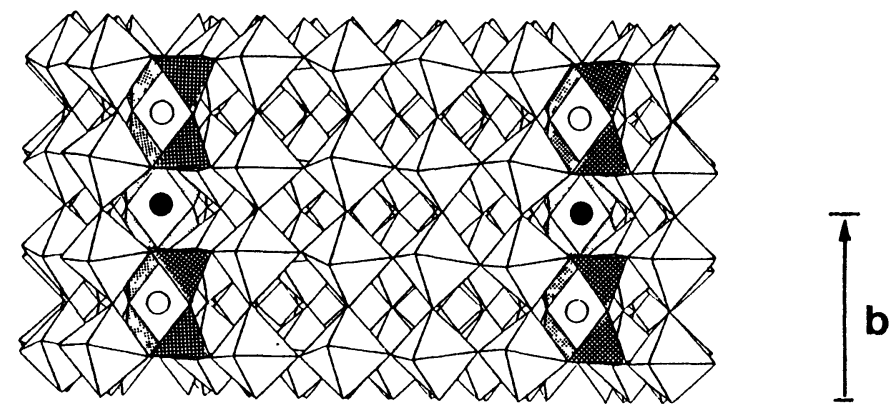

Fig. 7. $-[001]$ projection of $\mathrm{Ba}\left(\mathrm{P}_{2} \mathrm{O}_{4}\right)_{2}\left(\mathrm{WO}_{3}\right)_{16}$ structure (domain I). 
ED PATTERNS WITHOUT ANY SUPERSTRUCTURE SPOTS. - No evidence of contrast anomaly has been given which could be related to any superstructure phenomenon, but one must add that along [001] observation direction, crystals with superstructure spots on their ED pattern have been mainly selected.

ED PATTERNS WITH SUPERSTRUCTURE SPOTS. - Though superstructure spots often appear as bright as fundamental ones, contrast modulations may be observed only on thick areas of the crystal. These contrast modulations usually introduce the periodicity $2 a \times b$, centered, in agreement with the reflection existence conditions on ED patterns $(h k 0, h+k=2 n)$. Nevertheless, some crystals let appear this periodicity of the contrast on rather thin areas (Fig. 8). Thicker part of the crystal in figure 8 , shows an ordering of brighter dots, associated to the tunnel rows, which introduces the periodicity $a^{\prime} \times b^{\prime}$ centered with $a^{\prime}=2 a$ and $b^{\prime}=b$. A detail of a region close

a)
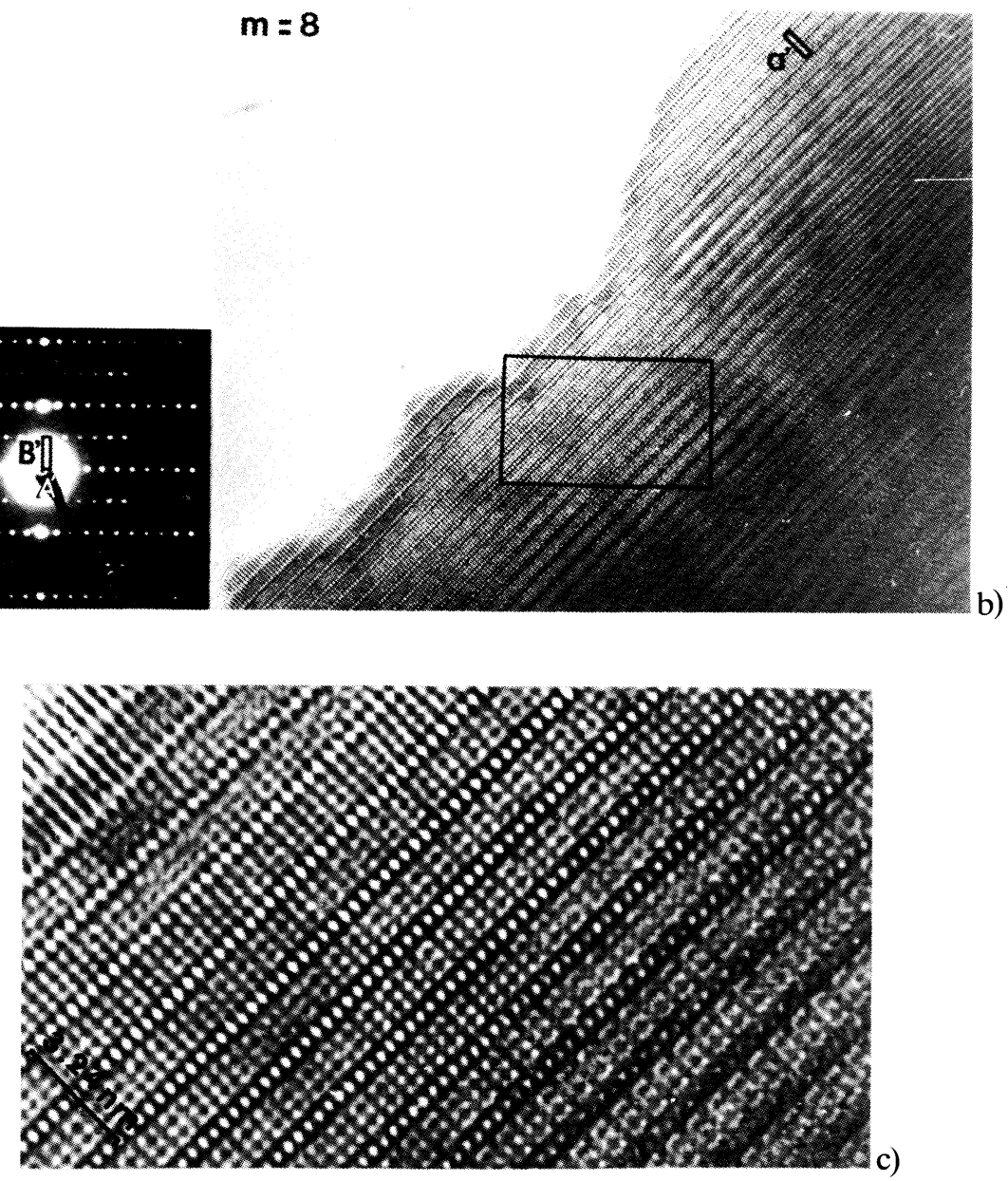

Fig. 8. - a) (001)* ED pattern with superstructure spots. b) corresponding high resolution image and c) detail, showing a distribution of brighter dots following the periodicity $a^{\prime}=2 a \times b$ centered even on rather thin area. 
to the edge (Fig. 8c) gives evidence of the same periodicity but on bright dots associated to the $\mathrm{ReO}_{3}$-type slabs of the structure. Figure 9 shows crystal images which suggest that the superstructure is not established throughout the crystal: whereas in a first zone, brighter dots introduce the periodicity $2 a \times b$ centered except on the edge (Fig. 9a), a second areas shows the same periodicity on the thicker part but local contrast modulation on the edge (Fig. 9b, c), which suggests a desordered variation of barium content in the hexagonal tunnels. In the same way, ED pattern in figure 10 , not only exhibits the superstructure spots but also diffuse streaks along [100]*. The corresponding images of different areas of the crystal show a regular $m=6$ crystal with a contrast modulation following the $2 a \times b$, centered periodicity, more or less intense. Thus, diffusion streaks may be related to a partial ordering of barium atoms in the tunnels. In order to verify that the phenomena of contrast modulations are directly related to variation of barium content in the hexagonal tunnels, image calculations have been performed.
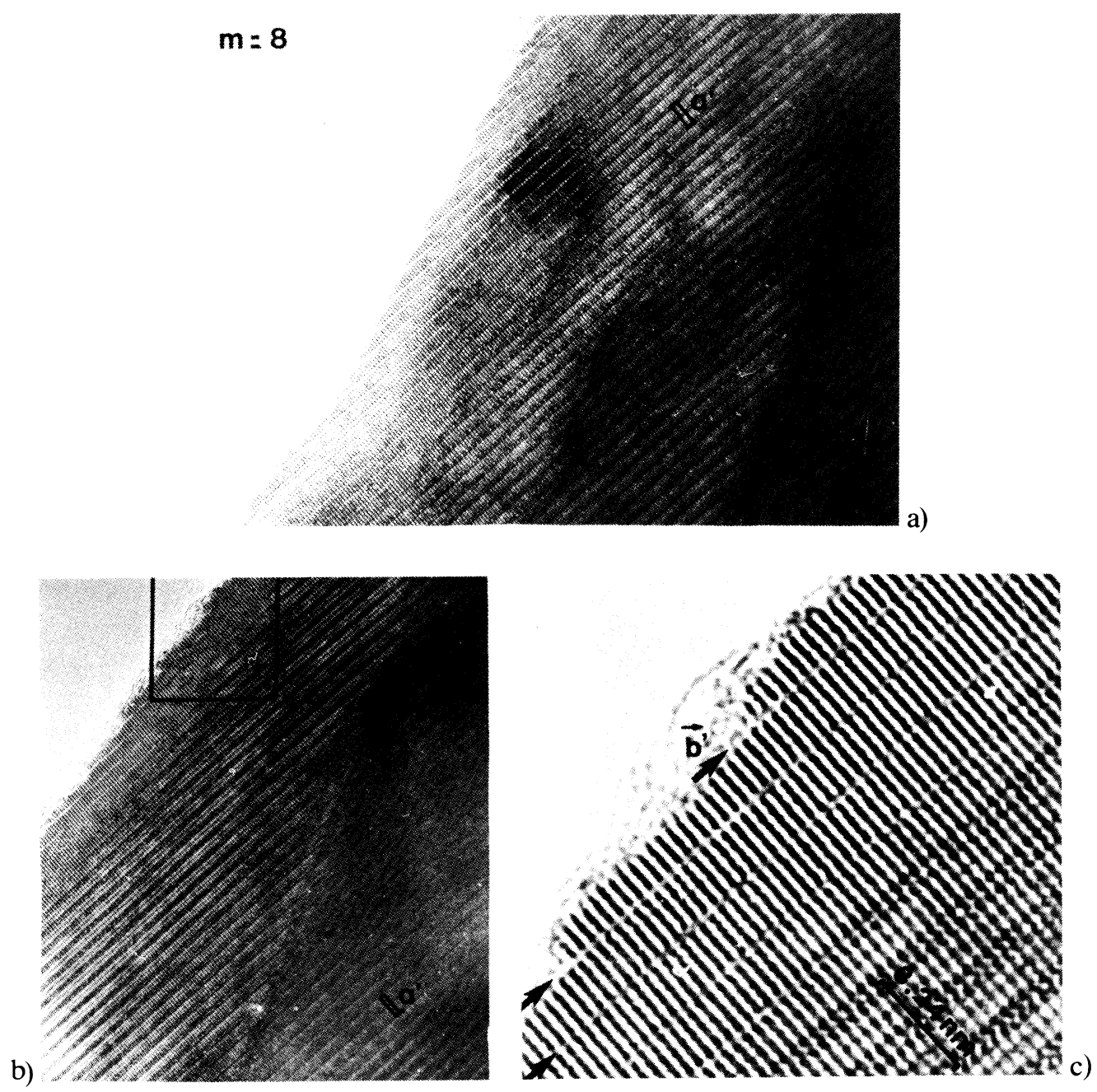

Fig. 9. - High resolution images of several areas of an $m=8$ crystal projected along [001]. The distribution of brighter dots follows the periodicity $a^{\prime}=2 a \times b$ centered a) on a wide area, b) only on a thick part where as c) on a detail of the crystal edge several tunnel rows show local modulations of the contrast (arrowed). 
a)

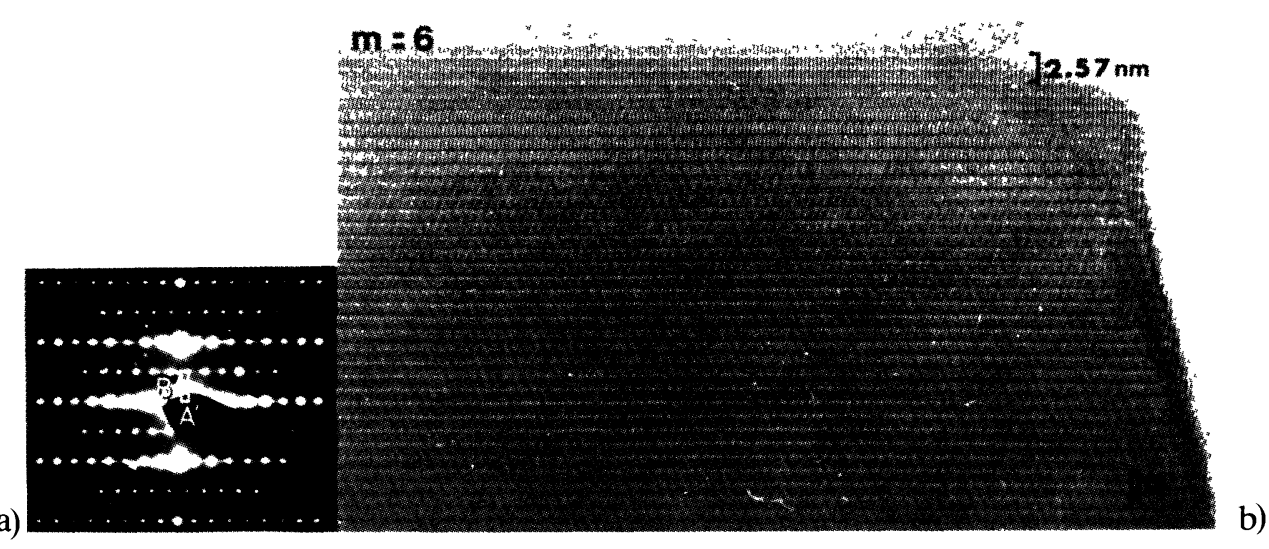

Fig. 10. - a) (001)* ED pattern with superstructure spots and diffuse streaks parallel to A. b) corresponding high resolution image showing no intergrowth phenomena but a distribution of brighter dots along the periodicity $a^{\prime}=2 a \times b$ centered.

\section{Image calculations.}

The point is to obtain calculated images as close as possible to the observed ones, i.e. showing the new periodicity : $a \times c$ along [010] and $2 a \times b$ centered along [001] (Fig. 11). The choice of a structural model was guided by the space group C $2 / \mathrm{m}$, established for the most common superstructure $2 a \times b \times c$ and the structural data given by the $\mathrm{X}$-ray single crystal study of $\mathrm{Ba}\left(\mathrm{P}_{2} \mathrm{O}_{4}\right)_{2}\left(\mathrm{WO}_{3}\right)_{16}$. The deduced model is projected onto (010) in figure 12 (parameters given in Tab. I) : binary axis positions ensure two sites ( $2 \mathrm{~b}$ and $2 \mathrm{c}$ ) for barium atoms, it allows thus to give different occupancy factors to either site. Two series of calculations have been performed with occupancy factors $\sigma_{2 b}=1$ and $\sigma_{2 c}=0.5$ or 0.75 corresponding to the formulations $2 \times\left[\mathrm{Ba}_{1.5}\left(\mathrm{P}_{2} \mathrm{O}_{4}\right)_{4}\left(\mathrm{WO}_{3}\right)_{32}\right]$ and $2 \times\left[\mathrm{Ba}_{1.75}\left(\mathrm{P}_{2} \mathrm{O}_{4}\right)_{4}\left(\mathrm{WO}_{3}\right)_{32}\right]$ respectively. Both are barium deficient compared to the classical composition in a double cell $2 \times\left[\mathrm{Ba}_{2}\left(\mathrm{P}_{2} \mathrm{O}_{4}\right)_{4}\left(\mathrm{WO}_{3}\right)_{32}\right]$. Figure 13 and 14 give the through-focus series calculated for different thickness values. Several remarks can be drawn :

(1) only some values of defocus allow to differentiate both sites of barium,

(2) their number does not increase with the thickness but with the difference in barium content,

(3) a thickness value being given, both observation directions allow to differentiate barium sites, but through a greater number of [001] images than [010] ones,

(4) the apparent localization of ordering, observed in figure 6 is consistent with these calculations, as the defocus value characteristic of barium content difference changes with the thickness,

(5) even the case $\sigma_{2 b}=1$ and $\sigma_{2 c}=0.75$ gives a too high barium content difference, as usually the crystal edges never show a contrast modulation (to be compared with the images calculated for a thickness of $3 \mathrm{~nm}$ ). This is in agreement with the fact that the smaller the difference of barium content, the less barium deficient the crystal will be. 

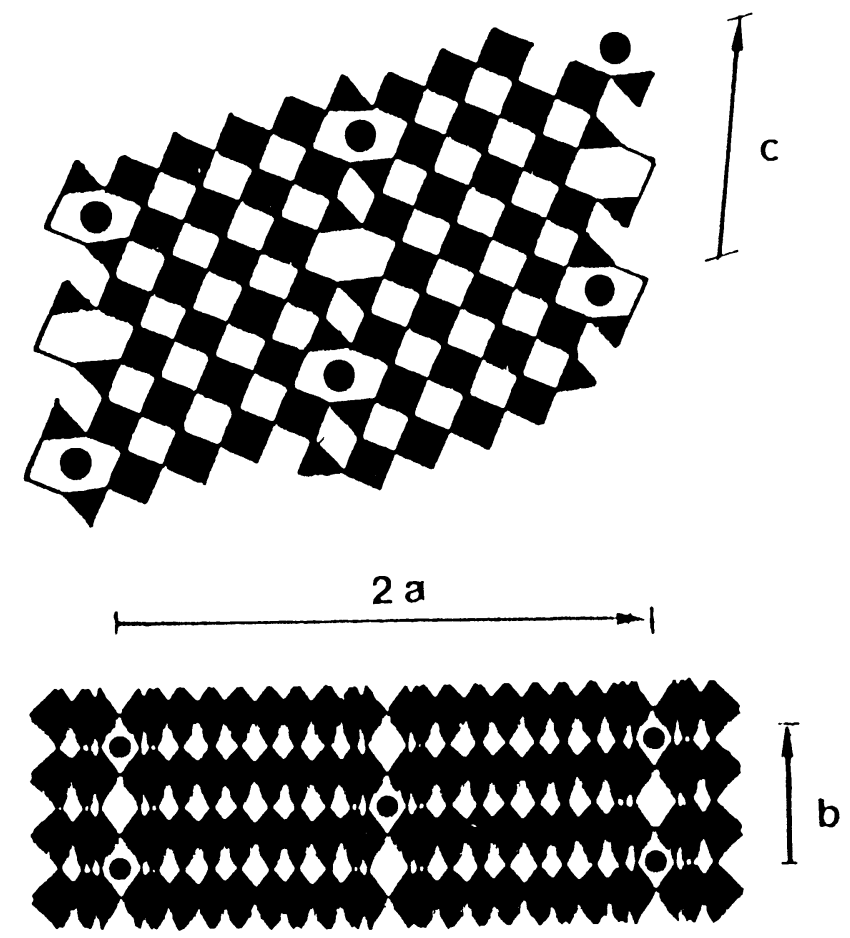

Fig. 11. - Idealized [010] and [001] projections summarizing the observed contrast : a) [010], $a \times c$ periodicity and b) [001], $2 a \times b$ centered periodicity.
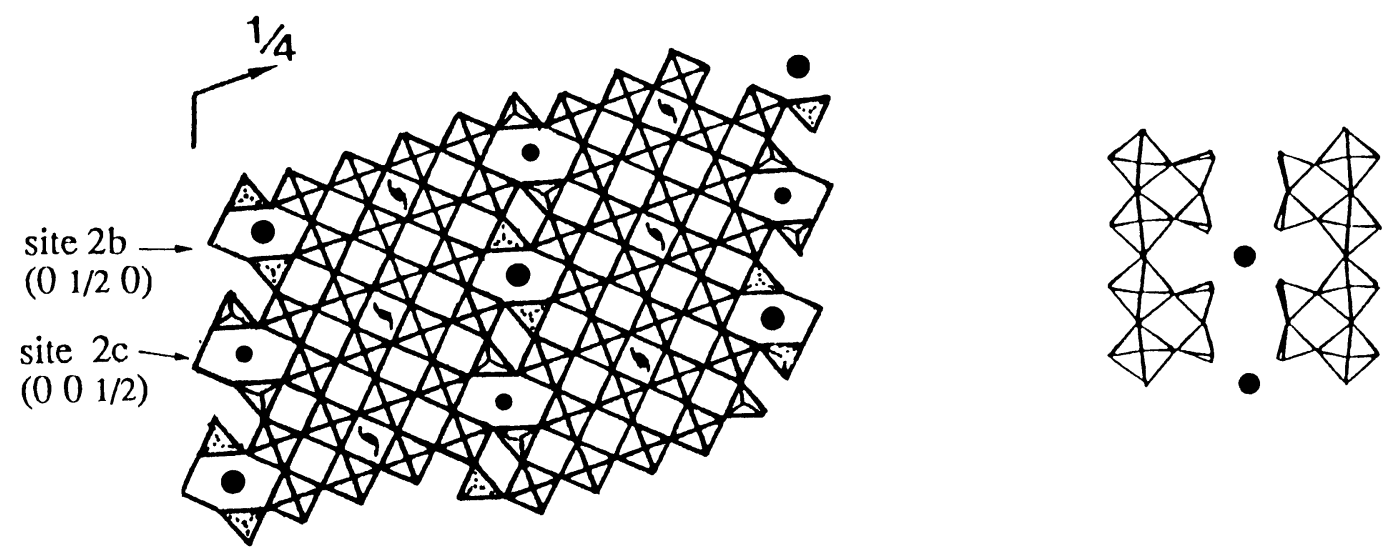

Fig. 12. - Idealized projection along [010] and [100] of the structural model used for image calculations. Binary axes and glide plane of $\mathrm{C} 2 / m$ space group are indicated. 
Table I. - Atomic parameters for $\mathrm{Ba}_{\sigma_{2 b}} \mathrm{Ba}_{\sigma_{2 c}}\left(\mathrm{P}_{2} \mathrm{O}_{4}\right)_{4}\left(\mathrm{WO}_{3}\right)_{32}$ superstructure model.

$a=3.582 \mathrm{~nm} ; b=0.748 \mathrm{~nm} ; c=1.706 \mathrm{~nm} ; \beta=114.74^{\circ} ;$ space group $C 2 / m$.

\begin{tabular}{|c|c|c|c|c|c|c|c|c|c|}
\hline atom & site & $x$ & $y$ & $z$ & atom & site & $x$ & $y$ & $z$ \\
\hline $\mathrm{Ba}$ & $2 b$ & 0 & 0.5 & 0 & O6 & $8 \mathrm{j}$ & 0.332 & 0.278 & 0.370 \\
\hline $\mathrm{Ba}^{\prime}$ & $2 c$ & 0 & 0 & 0.5 & $\mathrm{O}^{\prime}$ & $8 \mathrm{j}$ & 0.168 & 0.278 & 0.130 \\
\hline $\mathrm{P}$ & $8 \mathrm{j}$ & 0.032 & 0.299 & 0.673 & $\mathrm{O} 7$ & $8 \mathrm{j}$ & 0.088 & 0.280 & 0.010 \\
\hline $\mathrm{P}^{\prime}$ & $8 \mathrm{j}$ & 0.468 & 0.299 & 0.827 & O7' & $8 \mathrm{j}$ & 0.412 & 0.280 & 0.490 \\
\hline W1 & $8 \mathrm{j}$ & 0.1212 & 0.2461 & 0.1430 & $08 \mathrm{a}$ & $4 \mathrm{i}$ & 0.334 & 0.5 & 0.126 \\
\hline W1' & $8 \mathrm{j}$ & 0.3788 & 0.2461 & 0.3570 & O8 $\mathrm{a}^{\prime}$ & $4 i$ & 0.166 & 0.5 & 0.374 \\
\hline W2 & $8 \mathrm{j}$ & 0.0714 & 0.2441 & 0.8972 & O8b & $4 i$ & 0.325 & 0 & 0.116 \\
\hline W2' & $8 \mathrm{j}$ & 0.4286 & 0.2441 & 0.6028 & O8b' & $4 i$ & 0.175 & 0 & 0.384 \\
\hline W3 & $8 \mathrm{j}$ & 0.3246 & 0.2492 & 0.1127 & $09 a$ & $4 i$ & 0.070 & 0 & 0.893 \\
\hline W3' & $8 \mathrm{j}$ & 0.1754 & 0.2492 & 0.3873 & O9a' & $4 i$ & 0.430 & 0 & 0.607 \\
\hline W4 & $8 \mathrm{j}$ & 0.2760 & 0.2488 & 0.8706 & $\mathrm{O} 9 \mathrm{~b}$ & $4 i$ & 0.057 & 0.5 & 0.876 \\
\hline W4' & $8 \mathrm{j}$ & 0.2240 & 0.2488 & 0.6294 & O9b' & $4 \mathrm{i}$ & 0.443 & 0.5 & 0.624 \\
\hline O1 & $8 \mathrm{j}$ & 0.120 & 0.267 & 0.894 & O10 & $8 \mathrm{j}$ & 0.225 & 0.234 & 0.876 \\
\hline O1' & $8 \mathrm{j}$ & 0.380 & 0.267 & 0.606 & O10' & $8 \mathrm{j}$ & 0.275 & 0.234 & 0.624 \\
\hline $\mathrm{O} 2 \mathrm{a}$ & $4 i$ & 0.117 & 0.5 & 0.145 & 011 & $8 j$ & 0.439 & 0.284 & 0.362 \\
\hline $\mathrm{O} 2 \mathrm{a}^{\prime}$ & $4 i$ & 0.383 & 0.5 & 0.355 & 011' & $8 j$ & 0.061 & 0.284 & 0.138 \\
\hline $\mathrm{O} 2 \mathrm{~b}$ & $4 i$ & 0.110 & 0 & 0.117 & 012 & $8 j$ & 0.143 & 0.222 & 0.256 \\
\hline $\mathrm{O} 2 \mathrm{~b}^{\prime}$ & $4 i$ & 0.390 & 0 & 0.383 & O12' & $8 j$ & 0.357 & 0.222 & 0.244 \\
\hline $\mathrm{O} 3 \mathrm{a}$ & $4 i$ & 0.276 & 0.5 & 0.859 & 013 & $8 j$ & 0.044 & 0.210 & 0.767 \\
\hline O3a' & $4 i$ & 0.224 & 0.5 & 0.641 & O13' & $8 \mathrm{j}$ & 0.456 & 0.210 & 0.733 \\
\hline $\mathrm{O} 3 \mathrm{~b}$ & $4 i$ & 0.281 & 0 & 0.890 & O14 & $8 \mathrm{j}$ & 0.301 & 0.284 & 0.995 \\
\hline O3b' & $4 i$ & 0.219 & 0 & 0.610 & O14' & $8 j$ & 0.199 & 0.284 & 0.505 \\
\hline $\mathrm{O} 4$ & $4 i$ & 0.038 & 0.5 & 0.683 & 015 & $8 j$ & 0.250 & 0.250 & 0.750 \\
\hline O4' & $4 i$ & 0.462 & 0.5 & 0.817 & & & & & \\
\hline O5 & $8 \mathrm{j}$ & 0.011 & 0.220 & 0.885 & & & & & \\
\hline O5' & $8 \mathrm{j}$ & 0.489 & 0.220 & 0.615 & & & & & \\
\hline
\end{tabular}

(1) Every site is full except barium one, 2 c.

(2) Every atom has an isotropic thermal coefficient fixed to $B=1 \AA^{2}$.

\section{Concluding remarks.}

These results demonstrate that the superstructure commonly observed in the barium $\mathrm{DPTB}_{\mathrm{H}}$ 's is mainly due to the ordering of barium in the hexagonal tunnels. They show that the ordering takes place along both directions a and $\mathbf{c}$, but that the variation of barium content keeps rather low, i.e. $\Delta x$ smaller than 0.2 . The better sensitivity of electron diffraction to this kind of phenomena, compared to that of X-ray diffraction sheds some light on the single crystal study of the bronze $\mathrm{Ba}\left(\mathrm{P}_{2} \mathrm{O}_{4}\right)_{2}\left(\mathrm{WO}_{3}\right)_{16}[6]$. It suggests that the coexistence of both domains, I and II, observed in the latter study, which differ by the disposition of $\mathrm{P}_{2} \mathrm{O}_{7}$ groups and the tilting of $\mathrm{WO}_{6}$ octahedra in $\mathrm{ReO}_{3}$-type slabs, may be related to the same type of barium ordering as proposed in our superstructure model, which uses geometrical characteristics of structure I and II again. 
$\mathrm{BaBa} 0.5\left(\mathrm{P}_{2} \mathrm{O}_{4}\right)_{4}\left(\mathrm{WO}_{3}\right)_{32}$

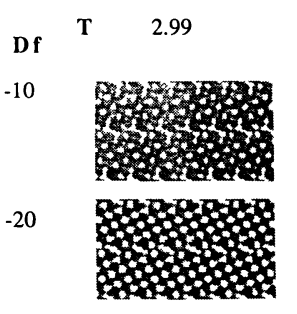

$-30$

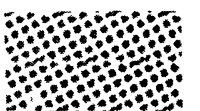

$-40$

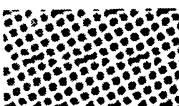

$-50$

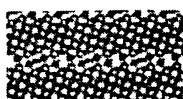

$-60$

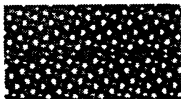

$-70$

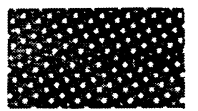

$-80$

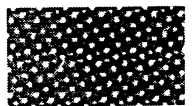

$-90$
5.99
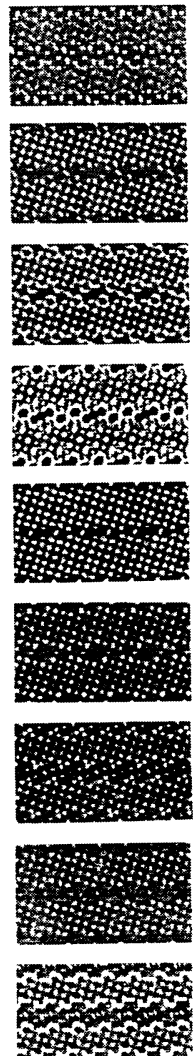

a)
$\mathrm{BaBa} 0.75\left(\mathrm{P}_{2} \mathrm{O}_{4}\right)_{4}\left(\mathrm{WO}_{3}\right)_{32}$

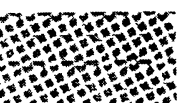

sto
8.98
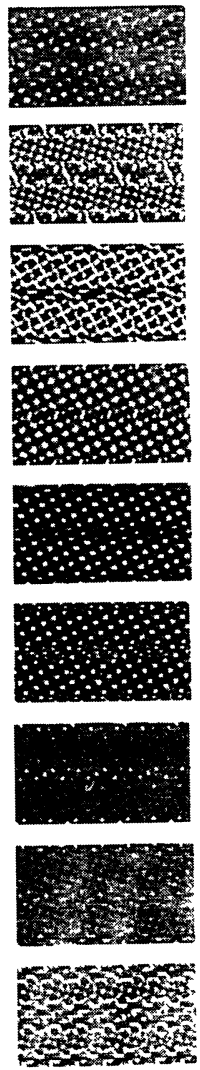

$-90$

$-80$
Df

$-10$

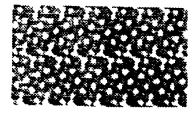

$-20$

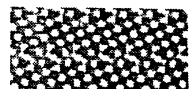

$-30$

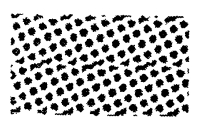

$-40$

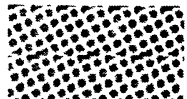

$-50$

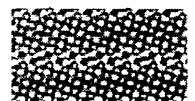

$-60$

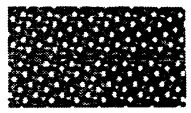

$-70$
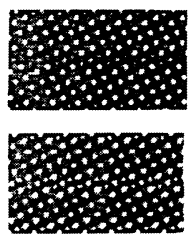

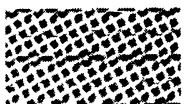

5.99
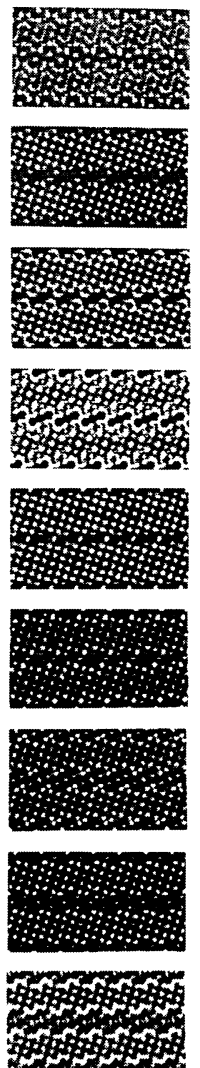

b)
8.98
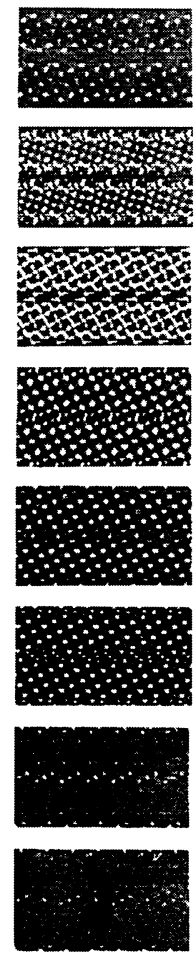

$6+4630$ 6ring

Fig. 13. - [010] through-focus series calculated with the parameters : high voltage $V=200 \mathrm{kV}$, spherical aberration $C_{\mathrm{s}}=0.8 \mathrm{~mm}$, convergence half-angle $\alpha / 2=0.8 \mathrm{mrad}$, focus spread $\Delta / 2=7.5 \mathrm{~nm}, 227$ beams in the objective aperture, barium occupancy on $\sigma_{2 \mathrm{c}}$ site, a) $0.5, \mathrm{~b}$ ) 0.75 (crystal thickness $T$ and defocus values $D f$ are given in nanometer). 


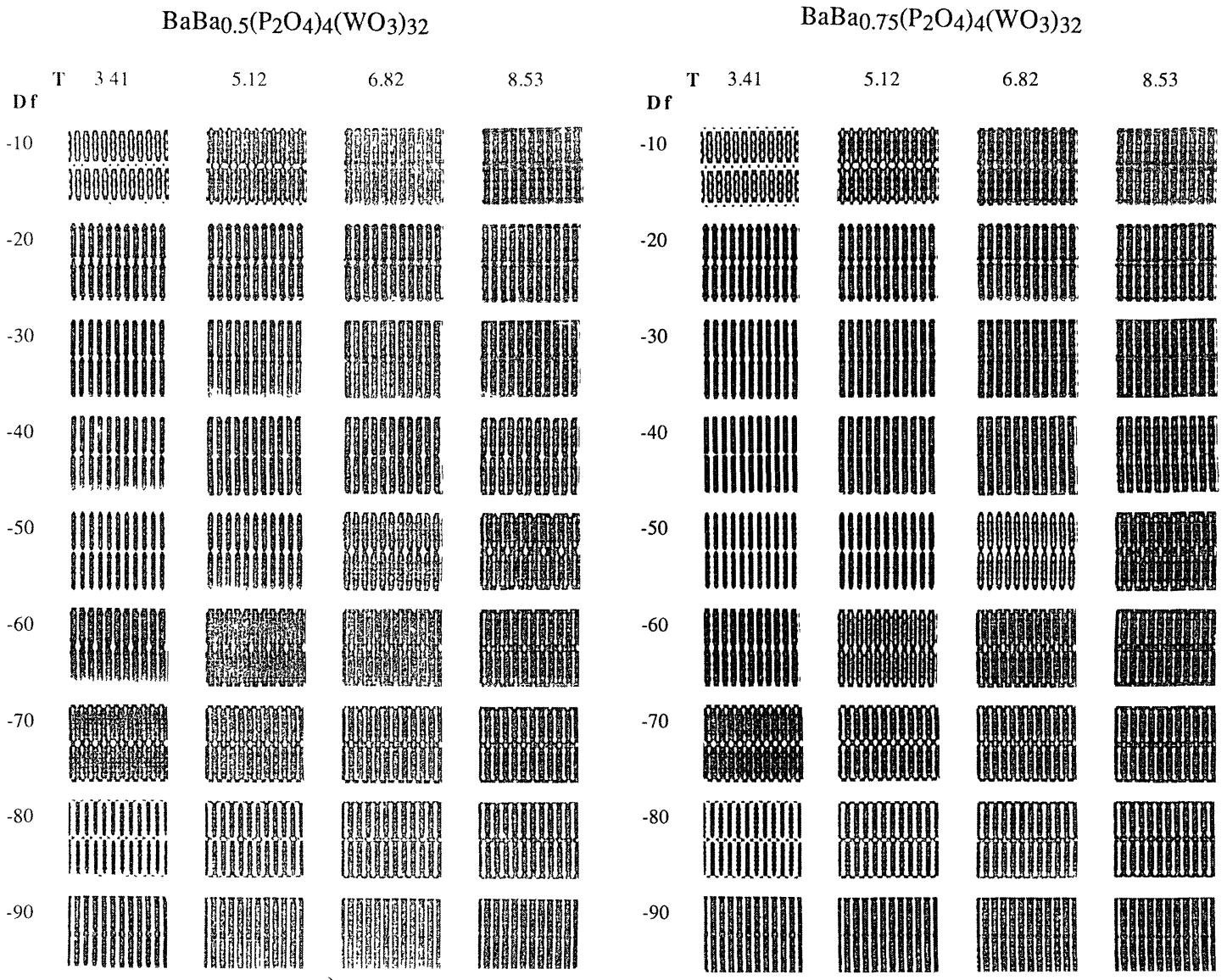

a)

b)

Fig. 14. - [001] through-focus series calculated with the parameters : $V=200 \mathrm{kV}, C_{\mathrm{s}}=0.8 \mathrm{~mm}$, $\alpha / 2=0.8 \mathrm{mrad}, \Delta / 2=7.5 \mathrm{~nm}, 281$ beams in the objective aperture, barium occupancy on $\sigma_{2 \mathrm{c}}$ site, a) 0.5 , b) 0.75 (crystal thicknesses $T$ and defocus values $D f$ are given in nanometer).

\section{References}

[1] HeRvieu M. and Raveau B., J. Solid. State Chem. 44 (1982) 299.

[2] Hervieu M. and RaVeau B., Chem. Scr. 22 (1983) 117.

[3] Hervieu M. and Raveau B., Chem. Scr. 44 (1983) 123.

[4] Domenges B., Hervieu M. and Raveau B., Acta Cryst. B40 (1984) 249.

[5] Giroult J. P., Goreaud M., LabBe Ph. and Raveau B., Acta Cryst. B36 (1980) 2570.

[6 LAMire M., LABBe Ph., Goreaud M. and Raveau B., J. Solid State Chem. 71 (1987) 342.

[7] O'KEEFE M., BUSECK P. R. and IIJIMA S., Nature 234 (1978) 322.

[8] HutChison M., Austis G. R. and Tilley R. J. D., Electron Microsc. 2 (1982) 57. 